\title{
Um caso de amor entre uma escola formal e uma escola de samba
}

\author{
Cristina Fernandes de Souza*
}

\section{A escola}

\section{A EMEF Comandante Garcia D' Ávila foi criada em 30 de} agosto de 1956 como Escola Mista do Imirim. Em 1958, foi rebatizada para II Escolas Agrupadas do Imirim. A partir de $1^{0}$ de abril de 1969, passou a ser denominada Escola Municipal de Ensino Fundamental Comandante Garcia D’Ávila e, desde então, está localizada na Rua Armando Coelho Silva, 859 - Parque do Peruche, em São Paulo, capital. Na década de 1950, a região ainda era área rural. A área onde hoje é o bairro Parque Peruche teve origem no loteamento da fazenda da família Peruche.

\section{0 bairro}

\section{A origem do bairro remonta ao século XVII. Há registros} de que, em 1616, onde hoje é a Escola Estadual Ary Barroso, Amador Bueno da Veiga mandou construir um casarão colonial e um moinho de trigo, evidentemente com mão-de-obra escrava, marcando a presença de negros e portugueses na região desde aquela época. Antigos moradores relatam que, nessa mesma edificação, foram encontrados utensílios de dominação dos escravos, como correntes, braceletes e outros (Marcelino, 2003).

Oficialmente, em 3 de abril de 1935, um médico, Doutor Francisco de Paula Peruche, adquiriu uma área de 929.330m², do antigo Sítio Mandaqui, que foi denominada Parque do Peruche, a partir dessa data. 0 bairro tem uma forma geométrica bem definida, resultado de um aproveitamento melhor do espaço para o loteamento. Assim, predominando a lógica da máxima valorização mercantilista do espaço, não foi criada nenhuma praça ou área de lazer. Além disso, muitos terrenos vendidos localizavamse em áreas baixas, sujeitas a alagamentos.

* Cristina Fernandes de Souza é comunicadora, da equipe Educação e Comunidade do CENPEC. Relato com base em entrevista com Waldir Romero, Diretor da EMEF Comandante Garcia D’ Ávila.
Foi nesse espaço que assentou moradia uma grande população de negros, vindos da região do Córrego do Saracura, onde hoje é a Av. 9 de Julho, na região do Bexiga, zona central da cidade de São Paulo. Os negros resgataram suas tradições e imprimiram sua cultura, desde as origens do Parque Peruche, daí a forte presença do samba no bairro.

Mais tarde, vieram muitos migrantes mineiros e do interior de São Paulo, além de portugueses, espanhóis e, em menor número, alemães, poloneses e iugoslavos. Posteriormente, a comunidade registrou uma chegada significativa de japoneses, especificamente da Ilha de Okinawa. Nos últimos anos, a solidariedade do bairro tem acolhido imigrantes vindos da América do Sul - bolivianos têm uma presença marcante nos espaços públicos. Nas escolas, escutamos o "portunhol" das conversas entre os alunos.

\section{Como tudo acabou em samba}

Há 11 anos, Waldir Romero é diretor da EMEF Comandante Garcia D’ Ávila, no Parque do Peruche. Waldir lembra que, quando chegou à escola, deparou-se com o que ele chamou de "berçário de segurança máxima": muitas grades, cadeados... Naquele tempo, a escola era conhecida como "maloquinha".

A EMEF Comandante Garcia D’ Ávila apresentava todos os índices negativos de aproveitamento escolar alto índice de evasão, absenteísmo, repetência. Além do uso de drogas dentro da escola, havia também muitos problemas relacionados à indisciplina, divisão em grupos, muitas brigas entre os alunos, desrespeito com os professores e funcionários, depredação, pichação nas paredes das salas e muros, móveis quebrados. A escola era desrespeitada e invadida. Os profissionais também desistiram da batalha. Não havia processo de construção coletiva, quase nenhum recurso pedagógico e a infra-estrutura era precária: o quadro era assustador. 


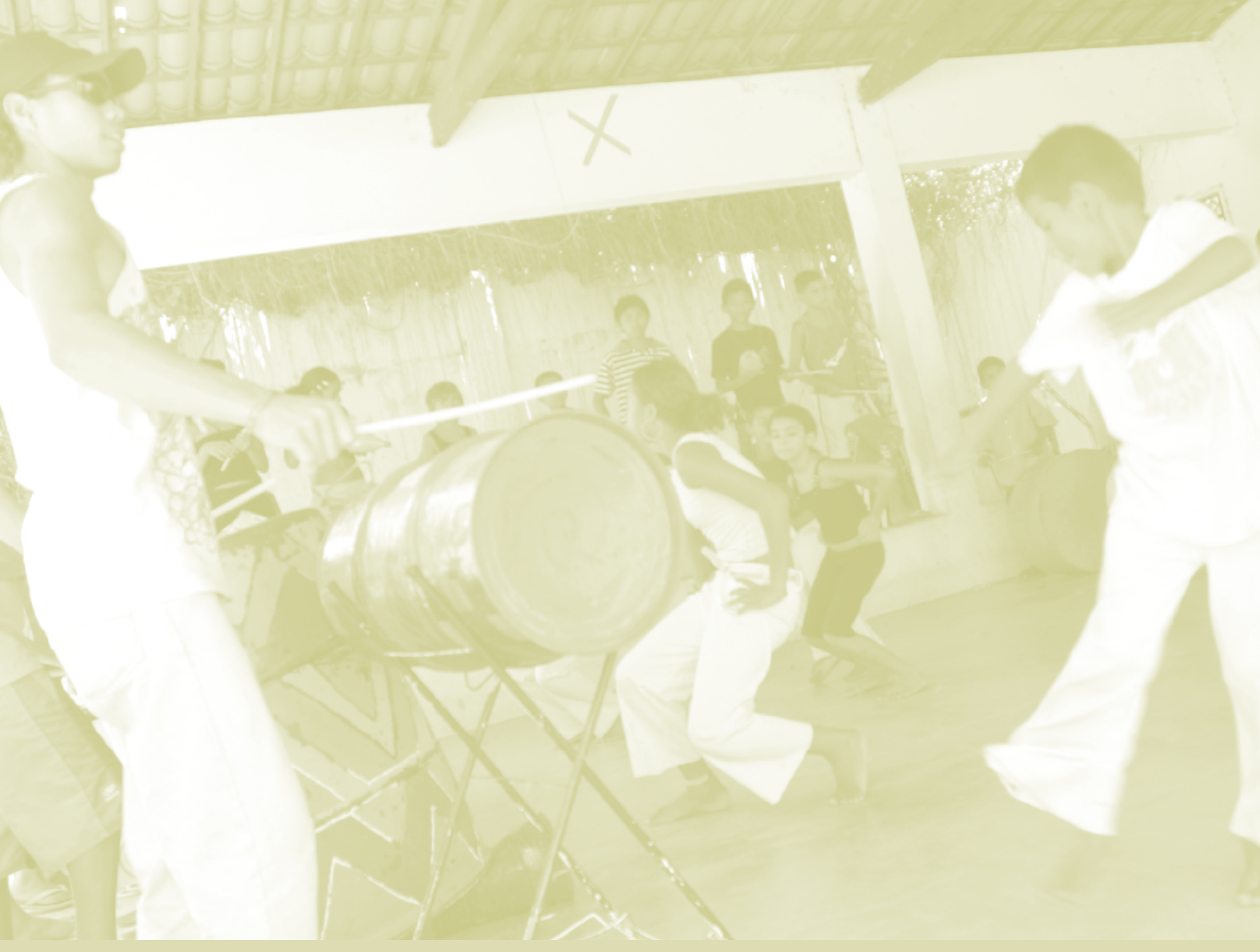

Foi longo o caminho percorrido de lá até o carnaval paulistano de 2006, no qual alunos da EMEF Comandante Garcia D' Ávila foram os responsáveis por pesquisar a vida de Santos Dumont, tema do samba-enredo da cinqüentenária Escola de Samba Unidos do Peruche. Além de participar da criação do samba-enredo, alunos, professores e funcionários da escola formaram uma ala com 112 participantes e desfilaram no sambódromo paulistano na noite de 25 de fevereiro de 2006.

Várias situações contribuíram para que o diretor Waldir se aproximasse das inúmeras escolas de samba do Parque do Peruche. Vindo de um outro bairro, o novo diretor não foi muito bem acolhido pela escola e seus alunos. Ao tentar equacionar os problemas de disciplina, estabelecendo canais de conversa para uma melhor convivência coletiva, Waldir escutou muitas vezes um: "Você não passa de um branco racista!" - rancoroso, enraivecido e seguido de uma expressão mista de desdém e desconfiança.

Ao constatar a influência das inúmeras escolas de samba existentes no bairro, Waldir decidiu se aproximar delas, buscando se envolver mais na comunidade. Começou a freqüentar os grêmios recreativos, estabelecer rela- ções com os líderes desses espaços, que também eram líderes comunitários naturais, dada a influência das escolas de samba na comunidade. Assim, Waldir foi se envolvendo, conhecendo a liturgia das escolas de samba, a linguagem do samba e, em suas palavras, "descobrindo as páginas ocultas da comunidade". Essa sua postura de se abrir para a comunidade resultou na conquista da confiança dos alunos da escola. Eles começaram a tratá-lo com mais respeito e empatia, depois de vê-lo "comemorando" com seus pais, tios, enfim, seus familiares que freqüentavam a escola de samba nos horários de lazer. Waldir já não era mais "um branco racista”, era "um dos nossos".

Outra situação que favoreceu a aproximação com as escolas de samba do bairro foi um momento em que a agremiação precisou passar por uma grande reforma. Era 1997. Waldir percebeu a necessidade de buscar alternativas de espaços de aprendizagem para que as crianças não fossem dispensadas das aulas. Ao explorar o bairro do Peruche, o diretor reconheceu a presença e a força que as várias escolas de samba tinham na comunidade e estabeleceu parcerias para utilizar estes e outros espaços - ruas, praças e cinemas - para o desenvolvimento 
de atividades educativas. Essa atitude não foi somente a procura por uma solução prática para um problema circunstancial, foi o reconhecimento de que a aprendizagem acontece em muitos espaços, e o processo educativo deve levar em conta as vivências, os valores, os saberes e os fazeres da comunidade local.

Waldir percebeu que deveria instigar, nos alunos, 0 sentimento de pertencimento à comunidade: "Tenho um bairro, um signo, um símbolo, uma história”. A escola era um excelente caminho, na medida em que oferecia seu espaço para eventos culturais próprios e de terceiros e atividades educativas. Nesse processo, Waldir resgatou as personalidades do bairro - muitos sambistas e esportistas, como Adhemar Ferreira da Silva, Éder Jofre e Basílio "Pé de Anjo".

O samba é tratado como tema transversal no currículo escolar. Os alunos da escola desenvolvem e confeccionam as fantasias nas aulas de Educação Artística e aprendem música com os compositores da escola de samba Unidos do Peruche. As aprendizagens são múltiplas e circulam em vários espaços. 0 carnaval é tratado como a festa de formatura.

0 diretor reconhece que o samba é a vocação do bairro, e que os meninos e meninas da comunidade alimentam o desejo de trabalhar com samba, construir uma carreira no carnaval. Daí a necessidade de gerar renda e emprego dentro dessa vocação, aproveitando as oportunidades existentes na comunidade. "Precisamos formar esses meninos para esse desafio”, vislumbra Waldir. Ele projeta um engajamento comunitário dos meninos e meninas, por meio da possibilidade de geração de renda.

"Na escola, alfabetiza-se pelo samba e pela arte", sintetiza Waldir, reconhecendo as aprendizagens além do currículo formal. A linguagem do samba é levada tão a sério que, em um encontro nacional de estudantes de medicina, sediado na escola em 2003, o Hino Nacional foi tocado pelos alunos em ritmo de samba, com muito orgulho e respeito, perante as autoridades do poder público, renomados acadêmicos e lideranças da comunidade.

A partir do estreitamento das relações com as escolas de samba da região - Unidos do Peruche, Morro da Casa Verde e Império da Casa Verde - outras parcerias foram construídas. Atualmente, a EMEF Comandante Garcia D' Ávila conta com valiosos voluntários, parcerias e apoios diversos. ${ }^{2}$

A escola criou um campo de relacionamento muito rico, uma verdadeira rede na comunidade. Alunos, pro- fessores e funcionários fazem parte desta trajetória e coIhem agora os frutos dessa conquista. Ao conversar com os profissionais e os meninos e meninas que estudam lá, nota-se o sentimento de pertencimento e acolhida e, sobretudo, o orgulho de fazer parte disso. A visibilidade que a escola atingiu é constatada nas várias parcerias estabelecidas e pela repercussão na mídia - o jornalista Gilberto Dimenstein escreveu recentemente uma crônica, na Folha de S.Paulo, citando a EMEF Garcia D’ Ávila e comentando sua presença no carnaval paulistano.

Hoje, a escola está muito bem cuidada, por todos alunos, professores e funcionários. Os funcionários limpam a escola com esmero, e as crianças aproveitam essa limpeza - brincando à vontade no chão dos corredores, ao mesmo tempo que a conservam. Não se vêem mais os muros pichados. 0 diretor Waldir até reservou um espaço em uma parede interna no pátio para a livre expressão artística por meio da linguagem do grafite, mas os alunos abriram mão desse exercício.

A escola abriu as portas para a comunidade. Seu amplo refeitório é reservado para a feijoada comunitária e se transforma em salão de festas para aniversários, casamentos e batizados. Em 2004, a população do bairro fez um delicioso bolo de 69 metros para comemorar os 69 anos do Parque Peruche; tudo foi feito na escola, desde os preparativos até os festejos. A EMEF Comandante Garcia D' Ávila participa do programa Escola Aberta, vibrando, nos finais de semana, com várias atividades esportivas, culturais e sociais, organizadas pela comunidade e para a comunidade. É uma relação simbiótica, na qual os relacionamentos se aprofundam, ampliam-se territórios e todos saem ganhando.

\section{Bibliografia}

MARCELINO, Márcio Michalczuk. A evolução urbana do Parque Peruche e sua gente. São Paulo: Editora Carthago, 2003.

\section{Notas}

1. Maloca: extraído do Dicionário de Língua Portuguesa Houaiss: a)conjunto de habitações de indígenas; aldeia. b) (1899) grande choça coberta de palmas secas, us. como habitação por várias famílias índias, esp. sul-americanas. c) Derivação: por extensão de sentido. Regionalismo: Brasil. Casa muito pobre, bastante rústica; choupana, rancho, barracão.

2. Universidades Mackenzie e FAAP, jornalista Gilberto Dimenstein, Amanakay, Projeto Sociedade das Crianças, APAE-PIPA, Labor, Prof. Mario Sergio Cortella, Profa. Lisete Arelaro, Senac, Futura Informática, Rotary de Bela Vista, Instituto Ives Otta, entre outros. 


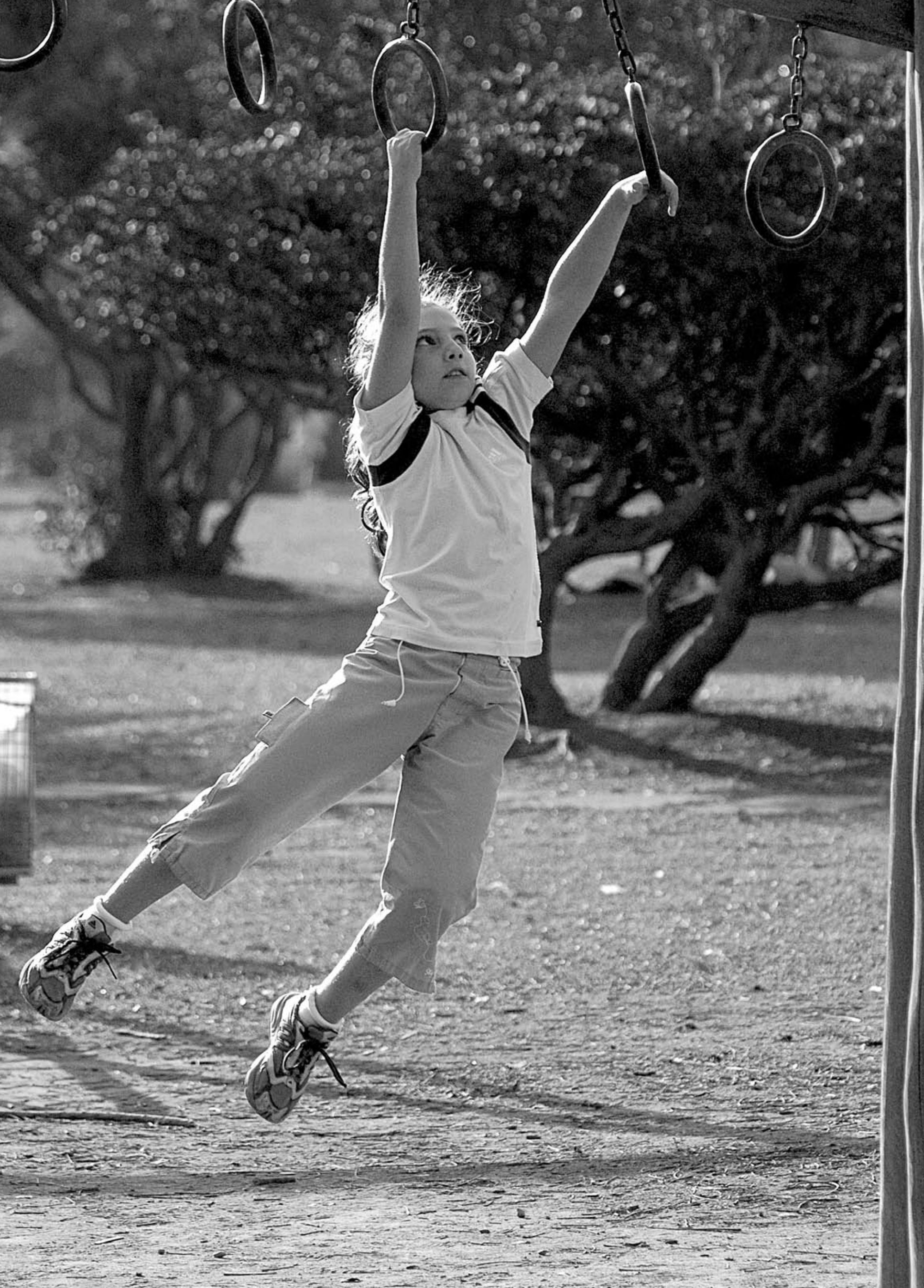

